\title{
On the Cultivation of Undergraduates' English Translation Ability in Smart Learning Environment
}

\author{
Xiaofang Wang ${ }^{1, a}$ and Cheng Liu' ${ }^{2, b^{*}}$ \\ School of Humanities, Jiangxi University of TCM, No. 1688 of Meiling Road, Wanli District, \\ Nanchang City, Jiangxi Province, China \\ School of Humanities, Jiangxi University of TCM, No. 1688 of Meiling Road, Wanli District, \\ Nanchang City, Jiangxi Province, China \\ a920711622@qq.com, bjxjzlc@163.com \\ * The Corresponding Author
}

\begin{abstract}
Keywords: Smart learning environment; Undergraduates; English translation ability
Abstract. In order to adapt to the new changes brought by globalization, College English teaching, especially translation teaching, must change the traditional mode and pay more attention to the cultivation of students' practice and application ability. This paper introduces the current situation of translation teaching, smart education and intelligent campus in our country. From the perspective of intelligent learning environment, it explores the training paths of undergraduate English translation ability, so as to promote their comprehensive English ability.
\end{abstract}

\section{The Present Situation of Translation Teaching}

At present, translation is simply defined as language skill training in China's College English teaching curriculum, which lacks systematicness in teaching content and pays little attention to the cultivation of translation ability. Translation teaching in the mainland of China started relatively late. The earliest MTI professional master was set up in January 2007. The statistics of translation teaching papers accounted for only $4.8 \%$ of the total published translation papers from 2000 to 2017, which is enough to prove the neglect of the academic field. In the statistics of the number of translation teaching papers, the largest proportion focuses on the teaching methods, and the research of modern science and technology and translation teaching, translation and other aspects of the testing and evaluation is very limited; the interdisciplinary study of translation teaching is less, accounting for only $2.8 \%$ of the total translation teaching, and basically concentrated in combining linguistics and translation teaching, which illustrates many translation researchers due to the subject category, it is difficult to find effective support in other areas. On the basis of the literature review, the author summarizes the outstanding problems in the study of translation teaching in China.

Firstly, teaching thesis focused on teaching model and teaching method, but it is difficult to find a better combined method to guide the translation teaching. Different scholars usually stick to their own argument. Secondly, crossover studies of translation teaching and linguistics are relatively rare. Although there are a small number of researchers exploring translation teaching from perspectives of linguistics, intercultural communication, researches involving psychology and education of social science and mathematics, computer science, natural science are really rare, which shows the lack of interdisciplinary researchers and the neglect of the study of the empirical translation teaching.

Thirdly, the combination studies of educational information technology and translation teaching are relatively limited. The bottleneck restricting this development is that we have too few talents who understand translation and are good at using modern science and technology, which is not conducive to the combination of the two. At present, the research methods of translation teaching still focus on speculative inquiry and teacher's self teaching experience. The lack of experimental data support and lack of persuasiveness are all the bottlenecks of restricting the progress of translation teaching research. 


\section{Introduction of Smart Education and Smart Campus}

The smart education is the new realm of the education information and the advanced stage of the digital education. The smart education relies on networking, cloud computing, big data technology, construct intelligent, instrumented, perceptive, ubiquitous ecological education system, construct intelligent learning environment of supporting collaborative learning and personalized learning, and realize deep integration of information technology and education business. Through the use of intellectual teaching method, we can promote learners to carry out the intellectual learning, and cultivate talents. In addition, intelligent education focuses on learners, provides micro learning, e-textbooks, mobile courseware, MOOCs and other open learning resources, and supports cloud learning, ubiquitous learning, seamless learning as well as other learning methods.

Smart campus refers to the use of the Internet, networking, virtualization and cloud computing and other new technology to change the interaction way of teachers, students and campus resources. It can integrate school teaching, scientific research, management, campus resources and application system, have a substantive change for the core elements of environment, teaching, education, learning, evaluate the response speed of the application of teaching and education, openness, personalization, flexibility and clarity, and realize the intelligent, humane, ecological, interactive and efficient service and management mode of campus. As an important category of intelligent campus research, it is becoming more and more important to build a good learning environment and promote the change of learning style.

\section{The Implementation of Cultivating Students' English Translation Ability in the Smart Learning Environment}

At present, the university campus has basically realized the full network coverage, and online education and teaching resources and platforms can be used anytime and anywhere in the school. This study analyzed the learning needs of students from the students' learning ability, determined the starting point, the online learning goals, learning resources and learning content, making use of intelligent learning environment to lead students break the limit of textbooks and classroom in English learning, expand English learning from classroom to the outside, and promote students' effective learning both in the real and virtual situation context. The teacher provides a series of English learning resources for students, a specific arrangement of learning tasks, let students complete the task through mobile phones or computers, the establishment of WeChat groups, QQ groups, to exchange learning experience and experiences, realize timely interaction, dynamic tracking and evaluation of the learning process and effect of the students. And the specific research content are as follows:

The students were divided into several groups, including 3-5 people in each group. One group leader was selected, who was mainly responsible for checking the completion of learning tasks, group learning preparation and group learning plan. The teachers share the teaching courseware and the related English learning audio, video and other materials, students can learn at anytime and anywhere in class. Teachers randomly check the completion of students' homework, record students' learning files, set up formative evaluation manuals, and make $30 \%$ achievements in the final exam, and guide students to learn actively.

Students are required to install VOA English learning software on the mobile phone (VOA Standard English), listening to 5 pieces of news every day extensively. They need to imitate and read two of the five news intensively, each about two minutes. A member of the study group is randomly selected to check other's learning. Teachers promptly pointed out and corrected the same problems of students, which aims to ensure the effectiveness of students'learning and their working hard for progress every day. VOA software with normal speed classifies all the news into different categories, updates practical news daily with Chinese translation, which can ensure the accuracy of students' reading. The software can be used online, and you can also download news after learning in the network environment, and support background playing. While listening and reading, we can click on any word for its definition, listen to the sound of the words and add to new word book. 
When in a network environment, automatic network will update to the interpretation the words of this view; through the law of memory processing for the previously stored words, students can master the words effectively. They can realize the sharing of the words in the web and mobile phone terminal end, and provide online dictionary query for the words used, help students to associate words when remembering the vocabulary. It also provides search function, search keywords of interest, search articles for listening and learning. It can be updated daily, obtain articles with the total amount more than 1000, support online and offline learning, record and analysze learning cases comprehensively. Students can intuitively grasp their own learning situation.

Students are required to install the software of Sea Word Dictionary on their mobile phones, to complete the "daily hot words" and "daily situational learning" learning every day. They can make use of the random function of CET-4 words to learn 20 random words every day, which is done by the team members together, and the team leader is responsible for the examination of records.

The teacher uses the net of www.pigai.org to assign the writing and translation tasks once in two weeks. This website is the largest English composition and writing platform in China. This platform can submit the composition corrections timely for students, immediately give composition scores and the feedback analysis, which can facilitate students to correct the composition while the iron is hot. The platform can point out the existence of errors in each sentence, writing spelling, grammar and vocabulary, collocation errors, and also give suggestions to revise the composition where there are mistakes. This website provides users with specific knowledge of the expansion of training, collocation recommendation and reference example, and provide comprehensive writing guidance for students, which can help students' autonomous learning. In addition, this website will identify the composition whether there is content repetition with the compositions of other students with each sentence as a unit after receiving students' submited essays and whether there is duplication and repetition with the internet corpus and provide the relevant repetition index for teachers' reference. It also records the growing process of the writing ability of a school, a class, or a specific student. This report is helpful for schools and teachers to grasp the weak points and weak points of schools and classes, and understand the changing trend of mastery degree of knowledge points, so as to provide data support for schools and teachers to plan English teaching.

Set up WeChat groups and QQ groups for the English classes. The teachers arrange the learning tasks, share the learning resources, summarize the learning effect and feedback information in the two communicating groups. Students can communicate in either group, share their learning experience, discuss the problems encountered in the study, and answer the questions of the students.

Our research adopts the evaluation form of formative evaluation and finality evaluation. Teachers observe and record students' extracurricular learning performance, make quantitative and qualitative evaluation for students' classroom performance through videos, photographs and other forms, including students' self-assessment, peer assessment and teacher evaluation, and establish the growth of students archives bag. The language teachers praise the student's progress and whim through language incentive evaluation, praise and encouragement evaluation, written evaluation and achievement display evaluation in the affirmative way, timely encourage and affirm students' efforts to protect the students active and quick thinking, maintain good classroom atmosphere, help every student to realize a comprehensive development and improve their ability to use English. Teachers test the effectiveness of student learning and the existing problems through final examinations and translation level tests, sum up experience, and further improve the quality of teaching.

\section{Conclusion}

Research has proved that using multiple smart education methods in smart environment can greatly promote students' enthusiasm and efficiency, and improve the educational quality of College English teaching. The mode of smart education should be paid attention to and popularized. 


\section{Acknowledgements}

Research of Education Science Planning Projects of $13^{\text {th }}$ Five-Year in Jiangxi Province (No: 17YB145); Key Project of Teaching Reform of Jiangxi University of Traditional Chinese Medicine (No: 2016jzzd-1); Research Project of Humanities and Social Science for Colleges and Universities in Jiangxi Province (No: YY162002).

\section{References}

[1] Education for a Smarter Planet: The Future of Learning. [DB/OL]. [2014-5-11]. http://www.redbooks.ibm.com/redpapers/pdfs/redp4564.pdf.

[2] E-Learning for Smart Classrooms. [DB/OL]. [2014-5-11]. http://education.qld.gov.au/smartclassrooms/documents/strategy/pdf/scbyte -elearning. pdf.

[3] National Education Technology Plan
[DB/OL]. [2014-5-11].http://www.ed.gov/sites/default/files/netp2010. pdf.

[4] Penn State Angel Course Management System. [EB/OL]. [2014-5-11]. https://cms.psu.edu/.

[5] Priorities for Excellence: The Penn State Strategic Plan 2009-10 through 2013-14. [DB/OL].[2014-5-11].http://strategicplan.psu.edu/Strategic Plancomplete.pdf.

[6] Priscilla Norton\& Karin M. Wiburg. Information Technology and Teaching Innovation[M]. Wu Hongjian, Ni Nanqi. Beijing: China Light Industry Press, 2002.

[7] Yong-Sang Cho. The Current Status and Future Development of Digital Publishing Industry in Korea[EB/OL].[2014-5-12].http//www.slideshare.net/zzosang/current-status-and-future-develo pment-koreayscho.Birmingham Metropolitan College creates "Classroom in the Cloud"[EB/OL]. http://www-01.ibm.com/software/success/cssdb.nsf/CS/STRD-8VGCBP?OpenDocument\&Site $=$ corp\&cty=en_us.

[8] Ministry of education. Ten Year Development Plan for Education Information [DB/OL]. [2014-5-11]. http://www.edu.cn/zong_he_870/20120330/t20120330_760603_5.shtml. 